\title{
Obesity: More Than an Inflammatory, an Infectious Disease?
}

\author{
Paola C. L. Leocádio ${ }^{1,2}$, Reinaldo B. Oriá ${ }^{3}$, Maria Elena Crespo-Lopez ${ }^{4}$ and \\ Jacqueline I. Alvarez-Leite ${ }^{\text {1* }}$
}

${ }^{1}$ Laboratório de Aterosclerose e Bioquímica Nutricional, Departamento de Bioquímica e Imunologia, Universidade Federal de Minas Gerais, Belo Horizonte, Brazil, ${ }^{2}$ Departamento de Nutrição, Escola de Enfermagem, Universidade Federal de Minas Gerais, Belo Horizonte, Brazil, ${ }^{3}$ Laboratório de Biologia da Cicatrização, Ontogenia e Nutrição de Tecidos, Faculdade de Medicina, Universidade Federal Do Ceará, Fortaleza, Brazil, ${ }^{4}$ Laboratório de Farmacologia Molecular, Instituto de Ciências Biológicas, Universidade Federal Do Pará, Belém, Brazil

Keywords: obesity, microbiota, diet, dysbiosis, inflammation

Much is discussed if obesity or diet components modify the "healthy" microbiota or if microbiota modifications trigger events that culminate in obesity. This association is probably reciprocal, and inflammation has crucial participation on it. We will discuss recent studies showing gut microbiome as an obesogenic factor and the mechanisms linked to the associated of diet, microbiota, and low-grade inflammation.

\section{CAN THE GUT MICROBIOTA REGULATE BODY WEIGHT?}

OPEN ACCESS

Edited by:

Harry Wichers,

Wageningen University \&

Research, Netherlands

Reviewed by:

Manuela Del Cornò,

Istituto Superiore di Sanità (ISS), Italy

${ }^{*}$ Correspondence:

Jacqueline I. Alvarez-Leite

jalvarezleite@gmail.com

Specialty section:

This article was submitted to

Nutritional Immunology,

a section of the journal

Frontiers in Immunology

Received: 10 September 2019 Accepted: 17 December 2019

Published: 14 January 2020

Citation:

Leocádio PCL, Oriá RB,

Crespo-Lopez ME and Alvarez-Leite Jl

(2020) Obesity: More Than an

Inflammatory, an Infectious Disease?

Front. Immunol. 10:3092.

doi: 10.3389/fimmu.2019.03092
Obesity is a growing epidemy, despite the efforts to contain it. The inflammation generated by the adipocyte hypertrophy and hyperplasia initiates crosstalk between adipocyte and resident macrophage (M2) in white adipose tissue (WAT). Once activated, both adipocyte and activated macrophage (M1) release several adipokines that trigger the infiltration of other immune cells such as neutrophils, CD8+ and CD4+ T cells (1). Tissue-resident innate lymphocytes also play an important role in the homeostasis of WAT and, consequently, in obesity. Although this resident lymphocyte plays regulatory and anti-inflammatory properties in non-obese individuals, obesity promotes changes in the profile of these cells (2). Invariant Natural Killer cells (iNKT) and mucosalassociated invariant T cells (MAIT) are important examples. The frequency of iNKT is reduced in WAT in obesity and is inversely related to the degree of obesity, insulin resistance and fasting blood glucose, suggesting that these cells play a role against metabolic disorders associated with obesity $(1,2)$. MAIT cells also present reduced frequency and change of phenotype in WAT in obesity, reducing IL-10 synthesis and gamma interferon (IFN $\gamma$ ) and increasing IL-17 production $(1,2)$ and can play an important role in the progression of inflammation (3).

Adipocytes also produce macrophage colony-stimulating factor (M-CSF-1), causing an increased influx of monocytes from bone marrow-derived precursors and regulating macrophage differentiation and survival $(4,5)$. The expanded WAT also secrets pro-inflammatory and prothrombotic factors such as interleukin (IL)-1 $\beta$, IL-6, tumoral necrosis factor (TNF), monocytes and macrophages chemoattractant protein (MCP-1/CCL2), C-reactive protein (CRP), tissue factor and factor VII, plasminogen activator inhibitor type-1 (PAI-1) (6). This pro-inflammatory, prothrombotic environment contributes to the onset of obesity-related complications such as metabolic syndrome, insulin resistance, hypertension, and systemic sterile inflammation.

One of the first studies linking obesity and microbiota was conducted by Ley et al. (7), showing that obesity is associated with a specific microbiota profile. The gut microbiota of healthy individuals is mostly composed of Firmicutes (70\%) and the Bacteroidetes (30\%). Other minor phyla are Actinobacteria, Proteobacteria, Fusobacteria, and Verrucomicrobia (8). The genetically obese ob/ob mice have in their microbiota 50\% fewer Bacterioidetes and a higher proportion 
of Firmicutes when compared to lean mice. This altered ratio between Firmicutes and Bacteroidetes (F/B ratio) has also been described in obese individuals (9). Nonetheless, obesity in adulthood is influenced by several factors besides the different profiles of gut microbiota and, until now, studies have not found enough consistency to point out specific obesogenic bacteria (10). However, preclinical studies revealed that the obesogenic microbiota profile could be transmitted from twins discordant for obesity to germ-free (GF) mice. When the fecal microbiota of the obese twin is transplanted to GF mice, the mice eventually become obese, the same occurring with the transplantation of microbiota from the lean twin to GF mice. Moreover, obesity was prevented when mice carrying the obese twin's microbiota were kept in the same cage with mice carrying the lean twin's microbiota (11).

\section{SINCE CHANGES IN MICROBIOTA PREDISPOSE TO OBESITY, WHAT DETERMINE THE TYPES OF BACTERIA THAT INHABIT THE GUT?}

The influence of microbiota on obesity development and low-grade inflammation seems to occur even before or immediately after birth. The gut-associated lymphoid tissues (GALT) are formed during embryogenesis and become mature during the microbial colonization, after birth. Bacterial antigens were recognized by the intestinal epithelium via pattern recognition receptors (PRR), such as Toll-like receptors (TLRs) and nucleotide-binding oligomerization domain 1 (NOD-1)
$(12,13)$. Changes in the microbial composition, which occur in the presence of obesity, disrupt the barrier integrity promoted by GALT, increase the intestinal permeability, favor bacterial translocation that triggers the inflammatory process (14).

Maternal obesity, caesarian section (CS), infections, and antibiotic utilization were described as factors influencing obesity (15) (Figure 1). Antibiotic therapy in the perinatal period is associated with intestinal microbiota disruption and metabolic changes sufficiently strong to affect body composition in late childhood $(16,17)$. Indeed, babies from mothers receiving antibiotics during the last gestational trimester presented an $84 \%$ higher risk of obesity (16). Moreover, CS is associated with the reduction in Bacteroidetes abundance and microbiota diversity in the first 2 years of life. Systemic levels of CXCL10 and CXCL11 chemokines were also reduced in children born by CS (17). Young adults born by CS have a higher risk for increased central and peripheral adiposity than those born by vaginal delivery (18). These associations are stronger in children whose mothers were obese compared to children of non-obese mothers (19).

\section{WHAT IS THE PARTICIPATION OF THE INFLAMMATION IN THIS SCENARIO?}

Previous studies clarified the crosstalk between the immune system and microbiota in obesity (20). The IgA is produced by intestinal $\mathrm{B}$ cells after interaction with $\mathrm{T}$ follicular helper cells (TFH) and secreted into the gut lumen covering bacteria membrane and reducing gut colonization (20, 21). Although bacteria-IgA binding participates in hosting defense against pathogens, IgA can also regulate the gene expression of

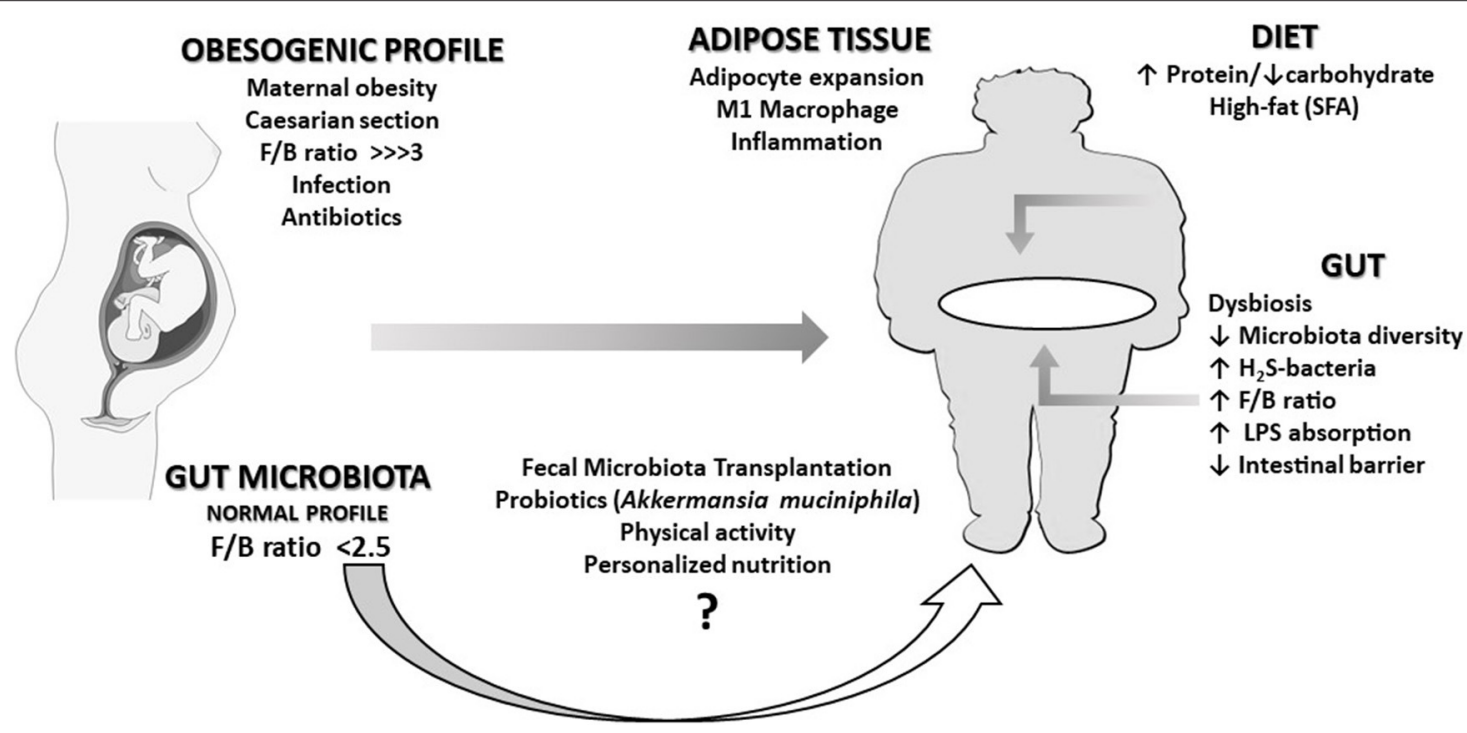

FIGURE 1 | An overview of the relationships described in this opinion paper. An obesogenic profile (characterized by a very high Firmicutes/Bacteroidetes ratio, F/B) can be caused in the fetus by conditions such as maternal obesity, caesarian section, infections, or antibiotics treatments during pregnancy. The immune and pro-inflammatory response caused by intestinal dysbiosis over life can eventually lead the individual to obesity in adulthood. This scenario can be worsened by the chronic intake of a high-fat diet, responsible for the increase of bacteria producing hydrogen disulfide $\left(\mathrm{H}_{2} \mathrm{~S}\right.$-bacteria) and pathogenic bacterial lipopolysaccharide (LPS) translocation. A healthy dietary pattern and physical activity may contribute to revert dysbiosis. Although probiotics and fecal microbiota transplantation could eventually improve this condition, presently, there is not enough clinical evidence supporting the adoption of such intervention. 
some gut bacteria population and intestinal cells. It has been proposed that IgA promotes colonization of a healthy microbiota reducing dysbiosis (22). It was tested in $\mathrm{MyD}^{-/-}$mice that develop obesity faster than controls and are defective in $\mathrm{TFH}$ and IgA (23). The expansion of WAT in $\mathrm{MyD}^{-/-}$is associated with the increase of Desulfovibrio and the loss of Clostridia populations. When mice were treated with antibiotics or replacement of Clostridia, the weight gain was reduced, confirming a cause-effect interaction (20). It suggests that by regulating IgA production, TFH cells maintain the intestinal Clostridia population, reducing fatty acids (FA) absorption and protecting the host against obesity.

Previous studies addressed the interaction of microbiota, and pro-inflammatory markers (24) showed that Bifidobacterium, Faecalibacterium, Ruminococcus, and Prevotella genus abundances were inversely associated with blood levels of CRP or pro-inflammatory cytokines (14, 25-29). Besides the abundance of a specific genus, gut microbial diversity has also been related to obesity. Individuals with low microbial diversity presented higher blood leukocyte count and CRP level that is related to higher triglyceridemia and lower high-density lipoprotein (HDL) levels, insulin resistance and increased risk of atherosclerosis-associated disorders (30).

The decrease in commensal bacteria levels and diversity (dysbiosis) permit the establishment of foreign bacteria, increasing the lipopolysaccharide (LPS) concentration in the gut lumen (Figure 1). LPS can reach systemic circulation by crossing the intestinal mucosa through altered tight junctional complex or linked to dietary fat incorporated into chylomicrons. In the plasma, LPS is transported bound to lipoproteins. Initially, LPS is transported in chylomicrons and then distributed to the other lipoproteins, mainly HDL (31). LPS increases the scavenger receptor binding to lipoproteins, as well as the endocytoses in endothelium and adipocytes. The expanded adipocytes and activated macrophages internalize LPS-rich lipoproteins (32), perpetuating the expansion and inflammation of the WAT. Indeed, LPS triggers the innate immune response on macrophages and adipocytes via TLR4 signaling, resulting in nuclear factor-kappa B (NF- $\kappa$ B) release and pro-inflammatory cytokine production $(14,33)$.

\section{HOW CAN THE DIET FAVOR THE OBESOGENIC MICROBIOTA?}

Previous studies have demonstrated the effect of high-fat diets (HFD) in increasing Firmicutes/Bacteroidetes ratio and in inducing dysbiosis (34-40) (Figure 1). Not only the amount of fat but also the type of FA may influence microbiota. Saturated FA (SFA) promotes dysbiosis by increasing $\mathrm{H}_{2} \mathrm{~S}$-bacteria, which results in the disruption of epithelial integrity by suppression of the tight junction proteins (41). Comparing the effects of HFD with different FAs, SFA quickly and persistently increased the proportion of $\mathrm{H}_{2} \mathrm{~S}$-bacteria over time. When SFA was replaced by $\omega 6$-polyunsaturated FAs ( $\omega 6$-PUFA), the proportion of $\mathrm{H}_{2} \mathrm{~S}$ bacteria remained stable, while replacing SFA for $\omega 3$-PUFA, the proportion of $\mathrm{H}_{2} \mathrm{~S}$-bacteria was reduced. This result aggregates beneficial effects to $\omega 3$-PUFA, a well-known systemic antiinflammatory agent.

HFD may also favor obesity not only by promoting dysbiosis but directly by favoring the entry of bacterial components such as LPS (42) (Figure 1). As mentioned before, the absorption of dietary fat facilitates the absorption of LPS since both are transported by chylomicron (43). In the WAT, LPS and palmitic acid increase expression of chemokines and cytokines such as MCP-1 and IL-1 $\beta$, and inflammation-related enzymes such cyclooxygenase-2, inducing macrophages infiltration and adipocyte expansion. In the liver, palmitic acid also increases the ceramide synthesis of CD36 and free-fatty-acid receptor-1 (FFA1/Gpr40) (41).

Protein-rich/carbohydrate-poor diet may also lead to dysbiosis, changes in barrier integrity and inflammatory activity. Unabsorbed proteins reach the colon, where microbiota exchanges fermentation substrate from carbohydrates to proteins, increasing colonic transit time and $\mathrm{pH}(41,44)$. Protein fermentation increases $\mathrm{H}_{2} \mathrm{~S}$, reactive oxygen species and ammonia production and reduces butyrate and Roseburia/Eubacterium abundance, suggesting a worse microbiota profile (45-47). Nonetheless, microbial metabolites from the proteolysis of the essential amino acid tryptophan also influence and modulate host microbiota. Indole groups bind aryl hydrocarbon receptor (AHR) that interfere with several metabolic steps, activate the immune system and reduce intestinal permeability (48).

The presence of non-digested carbohydrates in the colon increases the short-chain FAs produced by microbiota fermentation. These FAs can be absorbed and contribute to the host energy input. In addition to the additional energy absorption caused by short-chain FAs absorption, dysbiosis decreases the expression of FIAF (a lipase lipoprotein inhibitor), stimulating fat deposition in the WAT (33).

\section{HOW ARE WE FIGHTING OBESITY-RELATED DYSBIOSIS?}

Changing in diet and physical activity are crucial points in the treatment of obesity. Some studies suggest that such changes can alter not only bodyweight but also the microbiota in those individuals. The effects of physical activity modifying microbiota composition and metabolism have been studied, but the results are still controversial (49). Previous studies $(50,51)$ observed in HFD-fed animals that moderate and high-intensity exercise induced an abundance of Bacteroidetes in the colon. Nonetheless, an abundance of Firmicutes after physical exercise was also observed in animals with and without diabetes compared to sedentary ones (52). Thus, the influence of exercise on microbiota needs to be carefully evaluated.

Some of the well-established approaches, such as adopting a healthy dietary pattern (53-55), by reducing saturated fat and increasing fiber and antioxidant compounds intake $(56,57)$ have partially reverse dysbiosis and obesity in experimental studies. Nonetheless, it seems not to be enough to control obesity 
epidemy. Furthermore, new insights using pre and probiotics and fecal microbiota transplantation (FMT) have now been tested in humans (Figure 1).

Akkermansia muciniphila, which is a mucin-degrading bacterium that resides in the mucus layer, has been the most studied, mainly in animal models $(58,59)$. Clinical studies $(60,61)$ showed that, in overweight/obese individuals, the oral supplementation of $A$. muciniphila reduced insulin resistance and plasma total cholesterol and levels of blood markers for liver dysfunction and inflammation. However, there was only a modest effect on body weight and composition with $A$. muciniphila supplementation.

Although FMT could be a rational strategy to treat obesity-linked dysbiosis (62), few clinical studies have assessed FMT in individuals with metabolic syndrome or obesity (63-67). Results are until now disappointing, despite the improvement in insulin sensitivity seen in two studies $(66,67)$, none of them presented promising results in terms of weight loss or reduction in the inflammatory profile. It is confirmed by recent reviews $(68,69)$ reinforcing the need for studies evaluating the mechanisms by which FMT affect host metabolism and its long-term effects. Moreover, the best preparation, concentration and form of administration of FMT should be defined.

\section{REFERENCES}

1. Kane H, Lynch L. Innate immune control of adipose tissue homeostasis. Trends Immunol. (2019) 40:857-72. doi: 10.1016/j.it.2019.07.006

2. Del Cornò M, Conti L, Gessani S. Innate lymphocytes in adipose tissue homeostasis and their alterations in obesity and colorectal cancer. Front Immunol. (2018) 9:2556. doi: 10.3389/fimmu.2018.02556

3. Chehimi M, Vidal H, Eljaafari A. Pathogenic role of IL-17-producing immune cells in obesity, and related inflammatory diseases. J Clin Med. (2017) 6:68. doi: $10.3390 /$ jcm 6070068

4. Weisberg SP, McCann D, Desai M, Rosenbaum M, Leibel RL, Ferrante AW. Obesity is associated with macrophage accumulation in adipose tissue. J Clin Invest. (2003) 112:1796-808. doi: 10.1172/JCI2003 19246

5. Engin AB. Adipocyte-macrophage cross-talk in obesity. Adv Exp Med Biol. 960:327-43. doi: 10.1007/978-3-319-48382-5_14

6. Liu R, Nikolajczyk BS. Tissue immune cells fuel obesity-associated inflammation in adipose tissue and beyond. Front Immunol. (2019) 10:1587. doi: 10.3389/fimmu.2019.01587

7. Ley RE, Backhed F, Turnbaugh P, Lozupone CA, Knight RD, Gordon JI. Obesity alters gut microbial ecology. Proc Natl Acad Sci USA. (2005) 102:11070-5. doi: 10.1073/pnas.0504978102

8. Belizário JE, Faintuch J, Garay-Malpartida M. Gut microbiome dysbiosis and immunometabolism: new frontiers for treatment of metabolic diseases. Mediat Inflamm. (2018) 2018:1-12. doi: 10.1155/2018/2037838

9. Ley RE, Turnbaugh PJ, Klein S, Gordon JI. Human gut microbes associated with obesity Two. Nature. (2006) 444:1022-3. doi: 10.1038/4441022a

10. Castaner O, Goday A, Park YM, Lee SH, Magkos F, Shiow SATE, et al. The gut microbiome profile in obesity: a systematic review. Int J Endocrinol. (2018) 2018:1-9. doi: 10.1155/2018/4095789

11. Ridaura VK, Faith JJ, Rey FE, Cheng J, Duncan AE, Kau AL, et al. Gut microbiota from twins discordant for obesity modulate metabolism in mice. Science. (2013) 341:1241214. doi: 10.1126/science.1241214

12. Renz H, Brandtzaeg $\mathrm{P}$, Hornef $M$. The impact of perinatal immune development on mucosal homeostasis and chronic inflammation. Nat Rev Immunol. (2012) 12:9-23. doi: 10.1038/nri3112
In summary, the study of the complex network formed by gut microbiota, obesity, and inflammation are only in its first steps. The role of the dysbiosis in the genesis of obesity has been progressively uncovered, and the infectious component of this disease has gained more interest. However, up to date, no intervention based on microbes was able to reduce body weight effectively and persistently. Considering the relatively well-established relationship between microbiota and obesity in preclinical studies, additional efforts are necessary for the development of clinical interventions that support the microbiota manipulation as a realistic alternative to combat obesity.

\section{AUTHOR CONTRIBUTIONS}

PL and JA-L wrote the paper. MC-L and RO revised the paper.

\section{ACKNOWLEDGMENTS}

The authors thank the Fundação Cearense de Apoio ao Desenvolvimento Científico e Tecnológico (FUNCAP), Conselho Nacional de Desenvolvimento Científico e Tecnológico (CNPq), and Coordenação de Aperfeiçoamento de Pessoal de Nível Superior (CAPES) PROCAD 88881.068408/2014-01 for their support.

13. Bouskra D, Brézillon C, Bérard M, Werts C, Varona R, Boneca IG, et al. Lymphoid tissue genesis induced by commensals through NOD1 regulates intestinal homeostasis. Nature. (2008) 456:507-10. doi: 10.1038/nature07450

14. Gomes JMG, Costa J de A, Alfenas R de CG. Metabolic endotoxemia and diabetes mellitus: a systematic review. Metabolism. (2017) 68:133-44. doi: 10.1016/j.metabol.2016.12.009

15. Milani C, Duranti S, Bottacini F, Casey E, Turroni F, Mahony J, et al. The first microbial colonizers of the human gut: composition, activities, and health implications of the infant gut microbiota. Microbiol Mol Biol Rev. (2017) 81:e00036-17. doi: 10.1128/MMBR.00036-17

16. Mueller NT, Whyatt R, Hoepner L, Oberfield S, Dominguez-Bello MG, Widen EM, et al. Prenatal exposure to antibiotics, cesarean section and risk of childhood obesity. Int J Obes. (2015) 39:665-70. doi: 10.1038/ijo.2014.180

17. Jakobsson HE, Abrahamsson TR, Jenmalm MC, Harris K, Quince C, Jernberg C, et al. Decreased gut microbiota diversity, delayed Bacteroidetes colonisation and reduced Th1 responses in infants delivered by Caesarean section. Gut. (2014) 63:559-66. doi: 10.1136/gutjnl-2012-303249

18. Mesquita DN, Barbieri MA, Goldani HAS, Cardoso VC, Goldani MZ, Kac $\mathrm{G}$, et al. Cesarean section is associated with increased peripheral and central adiposity in young adulthood: cohort study. PLoS ONE. (2013) 8:e66827. doi: 10.1371/journal.pone.0066827

19. Blustein J, Attina T, Liu M, Ryan AM, Cox LM, Blaser MJ, et al. Association of caesarean delivery with child adiposity from age 6 weeks to 15 years. Int J Obes. (2013) 37:900-6. doi: 10.1038/ijo.2013.49

20. Petersen C, Bell R, Klag KA, Lee S-H, Soto R, Ghazaryan A, et al. T cellmediated regulation of the microbiota protects against obesity. Science. (2019) 365:eaat9351. doi: 10.1126/science.aat9351

21. Wang Y, Hooper L V. Immune control of the microbiota prevents obesity. Science. (2019) 365:316-17. doi: 10.1126/science.aay2057

22. Donaldson GP, Ladinsky MS, Yu KB, Sanders JG, Yoo BB, Chou WC, et al. Gut microbiota utilize immunoglobulin a for mucosal colonization. Science. (2018) 360:795-800. doi: 10.1126/science.aaq0926

23. Kubinak JL, Petersen C, Stephens WZ, Soto R, Bake E, O'Connell $\mathrm{RM}$, et al. MyD88 signaling in T cells directs IgA-mediated control of the microbiota to promote health. Cell Host Microbe. (2015) 17:153-63. doi: 10.1016/j.chom.2014.12.009 
24. van den Munckhof ICL, Kurilshikov A, ter Horst R, Riksen NP, Joosten LAB, Zhernakova A, et al. Role of gut microbiota in chronic low-grade inflammation as potential driver for atherosclerotic cardiovascular disease: a systematic review of human studies. Obes Rev. (2018) 19:1719-34. doi: $10.1111 /$ obr.12750

25. Le Chatelier E, Nielsen T, Qin J, Prifti E, Hildebrand F, Falony G, et al. Richness of human gut microbiome correlates with metabolic markers. Nature. (2013) 500:541-6. doi: 10.1038/nature12506

26. Cândido FG, Valente FXFX, Grześkowiak ŁM, Moreira APB, Rocha DMUP, Alfenas RCGet al. Impact of dietary fat on gut microbiota and low-grade systemic inflammation: mechanisms and clinical implications on obesity. Int J Food Sci Nutr. (2018) 69:125-43. doi: 10.1080/09637486.2017.1343286

27. Furet J-P, Kong L-C, Tap J, Poitou C, Basdevant A, Bouillot J-L, et al. Differential adaptation of human gut microbiota to bariatric surgery-induced weight loss. Diabetes. (2010) 59:3049-57. doi: 10.2337/db10-0253

28. Rajkumar H, Mahmood N, Kumar M, Varikuti SR, Challa HR, Myakala SP. Effect of probiotic (VSL\#3) and omega-3 on lipid profile, insulin sensitivity, inflammatory markers, and gut colonization in overweight adults: a randomized, controlled trial. Mediat Inflamm. (2014) 2014:348959. doi: $10.1155 / 2014 / 348959$

29. Martínez I, Lattimer JM, Hubach KL, Case JA, Yang J, Weber CG, et al. Gut microbiome composition is linked to whole grain-induced immunological improvements. ISME J. (2013) 7:269-80. doi: 10.1038/ismej.2012.104

30. Manco M, Putignani L, Bottazzo GF. Gut microbiota, lipopolysaccharides, and innate immunity in the pathogenesis of obesity and cardiovascular risk. Endocr Rev. (2010) 31:817-44. doi: 10.1210/er.2009-0030

31. Hersoug LG, Møller P, Loft S. Role of microbiota-derived lipopolysaccharide in adipose tissue inflammation, adipocyte size and pyroptosis during obesity. Nutr Res Rev. (2018) 31:153-63. doi: 10.1017/S09544224170 00269

32. Hersoug L-G, Møller P, Loft S. Gut microbiota-derived lipopolysaccharide uptake and trafficking to adipose tissue: implications for inflammation and obesity. Obes Rev. (2016) 17:297-312. doi: 10.1111/obr.12370

33. Muscogiuri G, Cantone E, Cassarano S, Tuccinardi D, Barrea L, Savastano S, et al. Gut microbiota: a new path to treat obesity. Int J Obes Suppl. (2019) 9:10-19. doi: 10.1038/s41367-019-0011-7

34. Turnbaugh PJ, Ley RE, Mahowald MA, Magrini V, Mardis ER, Gordon JI. An obesity-associated gut microbiome with increased capacity for energy harvest. Nature. (2006) 444:1027-31. doi: 10.1038/nature05414

35. Cani PD, Bibiloni R, Knauf C, Waget A, Neyrinck AM, Delzenne NM, et al. Changes in gut microbiota control metabolic endotoxemia-induced inflammation in high-fat diet-induced obesity and diabetes in mice. Diabetes. (2008) 57:1470-81. doi: 10.2337/db07-1403

36. Ding S, Chi MM, Scull BP, Rigby R, Schwerbrock NMJ, Magness S, et al. Highfat diet: bacteria interactions promote intestinal inflammation which precedes and correlates with obesity and insulin resistance in mouse. PLoS ONE. (2010) 5:e12191. doi: 10.1371/journal.pone.0012191

37. Nguyen SG, Kim J, Guevarra RB, Lee JH, Kim E, Kim SI, et al. Laminarin favorably modulates gut microbiota in mice fed a high-fat diet. Food Funct. (2016) 7:4193-201. doi: 10.1039/C6FO00929H

38. Turnbaugh PJ, Hamady M, Yatsunenko T, Cantarel BL, Duncan A, Ley $\mathrm{RE}$, et al. A core gut microbiome in obese and lean twins. Nature. (2009) 457:480-4. doi: 10.1038/nature07540

39. Araujo JR, Tomas J, Brenner C, Sansonetti PJ, Araújo JR, Tomas J, et al. Impact of high-fat diet on the intestinal microbiota and small intestinal physiology before and after the onset of obesity. Biochimie. (2017) 141:97-106. doi: 10.1016/j.biochi.2017.05.019

40. Ussar S, Griffin NW, Bezy O, Fujisaka S, Vienberg S, Softic S, et al. Interactions between gut microbiota, host genetics and diet modulate the predisposition to obesity and metabolic syndrome. Cell Metab. (2015) 22:51630. doi: 10.1016/j.cmet.2015.07.007

41. Wisniewski PJ, Dowden RA, Campbell SC. Role of dietary lipids in modulating inflammation through the gut microbiota. Nutrients. (2019) 11:E117. doi: 10.3390/nu11010117

42. Burcelin R, Garidou L, Pomié C. Immuno-microbiota cross and talk: the new paradigm of metabolic diseases. Semin Immunol. (2012) 24:67-74. doi: 10.1016/j.smim.2011.11.011
43. Erridge C, Attina T, Spickett CM, Webb DJ. A high-fat meal induces low-grade endotoxemia: evidence of a novel mechanism of postprandial inflammation. Am J Clin Nutr. (2007) 86:1286-92. doi: 10.1093/ajcn/86.5.1286

44. Roager HM, Hansen LBS, Bahl MI, Frandsen HL, Carvalho V, Gøbel RJ, et al. Colonic transit time is related to bacterial metabolism and mucosal turnover in the gut. Nat Microbiol. (2016) 1:16093. doi: 10.1038/nmicrobiol.2016.93

45. Geypens B, Claus D, Evenepoel P, Hiele M, Maes B, Peeters M, et al. Influence of dietary protein supplements on the formation of bacterial metabolites in the colon. Gut. (1997) 41:70-6. doi: 10.1136/gut.41.1.70

46. Nyangale EP, Mottram DS, Gibson GR. Gut microbial activity, implications for health and disease: the potential role of metabolite analysis. J Proteome Res. (2012) 11:5573-85. doi: 10.1021/pr300637d

47. Russell WR, Gratz SW, Duncan SH, Holtrop G, Ince J, Scobbie L, et al. Highprotein, reduced-carbohydrate weight-loss diets promote metabolite profiles likely to be detrimental to colonic health. Am J Clin Nutr. (2011) 93:1062-72. doi: $10.3945 /$ ajcn. 110.002188

48. Roager HM, Licht TR. Microbial tryptophan catabolites in health and disease. Nat Commun. (2018) 9:3294. doi: 10.1038/s41467-018-05470-4

49. Bianchi F, Duque ALRF, Saad SMI, Sivieri K. Gut microbiome approaches to treat obesity in humans. Appl Microbiol Biotechnol. (2019) 103:1081-94. doi: 10.1007/s00253-018-9570-8

50. Evans CC, LePard KJ, Kwak JW, Stancukas MC, Laskowski S, Dougherty $\mathrm{J}$, et al. Exercise prevents weight gain and alters the gut microbiota in a mouse model of high fat diet-induced obesity. PLoS ONE. (2014) 9:e92193. doi: 10.1371/journal.pone.0092193

51. Denou E, Marcinko K, Surette MG, Steinberg GR, Schertzer JD. Highintensity exercise training increases the diversity and metabolic capacity of the mouse distal gut microbiota during diet-induced obesity. Am J Physiol Endocrinol Metab. (2016) 310:E982-93. doi: 10.1152/ajpendo.00537.2015

52. Lambert JE, Myslicki JP, Bomhof MR, Belke DD, Shearer J, Reimer RA. Exercise training modifies gut microbiota in normal and diabetic mice. Appl Physiol Nutr Metab. (2015) 40:749-52. doi: 10.1139/apnm-2014-0452

53. Haro C, Garcia-Carpintero S, Alcala-Diaz JF, Gomez-Delgado F, DelgadoLista J, Perez-Martinez P, et al. The gut microbial community in metabolic syndrome patients is modified by diet. J Nutr Biochem. (2016) 27:27-31. doi: 10.1016/j.jnutbio.2015.08.011

54. Lopez-Legarrea P, Fuller NR, Zulet MA, Martinez JA, Caterson ID. The influence of Mediterranean, carbohydrate and high protein diets on gut microbiota composition in the treatment of obesity and associated inflammatory state. Asia Pac J Clin Nutr. (2014) 23:360-8. doi: 10.6133/apjen.2014.23.3.16

55. Del Chierico F, Vernocchi P, Dallapiccola B, Putignani L. Mediterranean diet and health: food effects on gut microbiota and disease control. Int J Mol Sci. (2014) 15:11678. doi: 10.3390/ijms150711678

56. Pandey KB, Rizvi SI. Plant polyphenols as dietary antioxidants in human health and disease. Oxid Med Cell Longev. (2009) 2:270-8. doi: 10.4161/oxim.2.5.9498

57. Roopchand DE, Carmody RN, Kuhn P, Moskal K, Rojas-Silva P, Turnbaugh PJ, et al. Dietary polyphenols promote growth of the gut bacterium Akkermansia muciniphila and attenuate high-fat diet-induced metabolic syndrome. Diabetes. (2015) 64:2847-58. doi: 10.2337/db14-1916

58. Chelakkot C, Choi Y, Kim DK, Park HT, Ghim J, Kwon Y, et al. Akkermansia muciniphila-derived extracellular vesicles influence gut permeability through the regulation of tight junctions. Exp Mol Med. (2018) 50:e450-11. doi: $10.1038 / \mathrm{emm} .2017 .282$

59. Li J, Lin S, Vanhoutte PM, Woo CW, Xu A. Akkermansia muciniphila protects against atherosclerosis by preventing metabolic endotoxemiainduced inflammation in apoe ${ }^{-/-}$mice. Circulation. (2016) 133:2434-46. doi: 10.1161/CIRCULATIONAHA.115.019645

60. Depommier C, Everard A, Druart C, Plovier H, Van Hul M, Vieira-Silva $\mathrm{S}$, et al. Supplementation with Akkermansia muciniphila in overweight and obese human volunteers: a proof-of-concept exploratory study. (2019). 25:1. doi: 10.1038/s41591-019-0495-2

61. Dao MC, Everard A, Aron-Wisnewsky J, Sokolovska N, Prifti E, Verger EO, et al. Akkermansia muciniphila and improved metabolic health during a dietary intervention in obesity: relationship with gut microbiome richness and ecology. Gut. (2016) 65:426-36. doi: 10.1136/gutjnl-2014-308778 
62. Lee P, Yacyshyn BR, Yacyshyn MB. Gut microbiota and obesity: an opportunity to alter obesity through faecal microbiota transplant (FMT). Diabetes, Obes Metab. (2019) 21:479-90. doi: 10.1111/dom.13561

63. Allegretti JR, Kassam Z, Mullish BH, Chiang A, Carrellas M, Hurtado J, et al. Effects of fecal microbiota transplantation with oral capsules in obese patients. Clin Gastroenterol Hepatol. (2019) doi: 10.1016/j.cgh.2019.07.006. [Epub ahead of print].

64. Allegretti JR, Mullish BH, Kelly C, Fischer M. The evolution of the use of faecal microbiota transplantation and emerging therapeutic indications. Lancet. (2019) 394:420-31. doi: 10.1016/S0140-6736(19)31266-8

65. Smits LP, Kootte RS, Levin E, Prodan A, Fuentes S, Zoetendal EG, et al. Effect of vegan fecal microbiota transplantation on carnitine- and cholinederived trimethylamine-N-oxide production and vascular inflammation in patients with metabolic syndrome. J Am Heart Assoc. (2018) 7:e008342. doi: 10.1161/JAHA.117.008342

66. Vrieze A, Van Nood E, Holleman F, Salojärvi J, Kootte RS, Bartelsman JFWM, et al. Transfer of intestinal microbiota from lean donors increases insulin sensitivity in individuals with metabolic syndrome. Gastroenterology. (2012) 143:913-16.e7. doi: 10.1053/j.gastro.2012.06.031

67. Kootte RS, Levin E, Salojärvi J, Smits LP, Hartstra AV, Udayappan SD, et al. Improvement of insulin sensitivity after lean donor feces in metabolic syndrome is driven by baseline intestinal microbiota composition. Cell Metab. (2017) 26:611-19.e6. doi: 10.1016/j.cmet.2017.09.008

68. Aron-Wisnewsky J, Prifti E, Belda E, Ichou F, Kayser BD, Dao MC, et al. Major microbiota dysbiosis in severe obesity: fate after bariatric surgery. Gut. (2019) 68:70-82. doi: 10.1136/gutjnl-2018-316103

69. Zhang Z, Mocanu V, Cai C, Dang J, Slater L, Deehan EC. Impact of fecal microbiota transplantation on obesity and metabolic syndromea systematic review. Nutrients. (2019) 11:2291. doi: 10.3390/nu11 102291

Conflict of Interest: The authors declare that the research was conducted in the absence of any commercial or financial relationships that could be construed as a potential conflict of interest.

Copyright (c) 2020 Leocádio, Oriá, Crespo-Lopez and Alvarez-Leite. This is an openaccess article distributed under the terms of the Creative Commons Attribution License (CC BY). The use, distribution or reproduction in other forums is permitted, provided the original author(s) and the copyright owner(s) are credited and that the original publication in this journal is cited, in accordance with accepted academic practice. No use, distribution or reproduction is permitted which does not comply with these terms. 